\title{
PENGOLAHAN DATA PRODUKSI PADI SAWAH MELALUI KELOMPOK TANI MENGGUNAKAN BAHASA PEMROGRAMAN
}

(Studi Kasus pada Kantor Kepala Desa Tanjung Pauh Mudik Kabupaten Kerinci Provinsi Jambi)

Radike, M.Kom.

Sekolah Tinggi Manajemen Informatika dan Komputer (STMIK) GICI

Email, Khinchay11@gmail.com

\begin{abstract}
ABSTRAK
Dalam proses pengambilan data dilakukan langsung pada Kantor Kepala Desa Tanjung Pauh Mudik untuk mendapatkan data dan untuk mengetahui kendala-kendala apa saja yang dihadapi oleh Kantor Kepala Desa tersebut di dalam proses pengolahan data produksi padi sawah. Pada sistem yang sedang berjalan, pengolahan data produksi padi sawah masih dilakukan secara manual sehingga informasi yang dihasilkan kurang efisien dan efektif.

Adapun usaha-usaha untuk menerapkan sistem tersebut adalah dengan cara membandingkan sistem yang lama dengan sistem yang baru, untuk merombak dari sistem yang lama kesistem yang baru telah terlebih dahulu mendapatkan perbandingan antara kedua sistem yang diterapkan dan memilih dari sistem tersebut yang rasanya akan membawa keuntungan bagi Kantor Kepala Desa atau instansi tersebut.
\end{abstract}

Kata kunci : Pengolahan data, produksi, $V b 6.0$

\section{ABSTRACT}

In the research the write directly did the research to the Kantor Kepala Desa Tanjung Pauh Mudik to get the data and to find the problems foced by the Kantor kepala Desa in the process produce paddy rice field through group farmer at office lead country side foreland. Currently, data processing system production rice field still counducted manual system. It makes the information gathered is in effective.

The effont to apply the system is by comparing old systemand new system. To change the old system to the new system, firstly both systems have to be compared finally, choose the effective system for Kantor Kepala Desa or the instansion.

\section{PENDAHULUAN}

\section{Latar Belakang}

Perkembangan dunia zaman sekarang ini diberbagai bidang kehidupan baik dalam bidang ekonomi, sosial, budaya, politik dan dunia pendidikan selalu dituntut untuk memberikan segala sesuatu dengan cepat, tepat dan akurat baik dalam pemprosesan data maupun dalam penyajian informasi yang dibutuhkan.

Seiring dengan derap langkah pembangunan dewasa ini bahwa pekerjaan yang dihadapi manusia kian hari kian rumit. Untuk itulah setiap perusahaan, industri baik pemerintah maupun swasta yang ada di indonesia harus mengikuti perkembangan ilmu pengetahuan dan teknologi. Salah satu bentuk 
kemajuan perkembangan IPTEK tersebut adalah dalam bidang ilmu informasi yang menggunakan teknologi komputer.

Sehubungan dengan hal ini tersebut teknologi komputer merupakan salah satu alat bantu pengolahan data agar data tersebut dapat berguna dalam pengambilan suatu keputusan penting yang dapat diakses/dimanfaatkan oleh orang atau organisasi baik pemerintah maupun swasta untuk mengantisifasi tuntutan diatas dalam masa sekarang ini. Hal ini disebabkan komputer melakukan pekerjaan yang berulangrulang dalam waktu yang relatif singkat dan mampu menyajikan informasi dengan cepat, tepat, akurat dan juga dalam komputerisasi sekarang ini, betapa pentingnya jasa dan informasi disamping ilmu lainnya. Hasil-hasil yang dicapai dalam bidang ilmu pengetahuan dan teknologi mengakibatkan banyaknya perubahan-perubahan yang terjadi terutama dibidang administrasi dan manajemen.

Pada Kantor Kepala Desa Tanjung Pauh Mudik telah menggunakan komputer untuk mendapatkan laporan data pegawai setiap bulannya. Pentingnya peranan komputer dalam sistem informasi disebabkan besarnya volume data yang akan diolah pada suatu bidang. Pada Kantor Kepala Desa Tanjung Pauh Mudik pengolahan data telah menggunakan tetapi masih digunakan belum efektif.

Didasari atas hambatan-hambatan dan kelemahan diatas penulis tertarik untuk mendesain suatu sistem baru dengan mengaplikasikan bahasa pemrograman Visual Basic Versi 6.0 dalam pengolahan data produksi padi sawah, oleh karena itu untuk mencapai halhal diatas penulis memilih judul skripsi dengan judul "Sistem Pengolahan Data Produksi Padi Sawah Melalui Kelompok Tani Pada Kantor Kepala Desa Tanjung Pauh Mudik Menggunakan Bahasa Pemrograman Visual Basic 6.0".

\section{Perumusan Masalah}

Perumusan masalah yang akan penulis ajukan disini adalah:

1. Bagaimana jika suatu sistem/cara yang belum efektif di implementasikan dengan penggunaan komputer.

2. Apakah dengan adanya sistem baru ini akan mempermudah dan menjadi efisien pada user yang membutuhkannya ?

3. Rumitnya melakukan perbaikan atau penghapusan data produksi padi sawah.

\section{Ruang Lingkup Penelitian}

Berdasarkan latar belakang dan rumusan masalah dalam penulisan skripsi ini maka menghindari penyimpangan dalam penelitian ini penulis hanya membatasi objek prosedur atau sistem yang mana pada penelitian ini hanya dibatasi Pengolahan Data Produksi Padi Sawah Melalui Kelompok Tani Pada Kantor Kepala Desa Tanjung Pauh Mudik.

\section{Tujuan Dan Manfaat Penelitian}

Adapun manfaat dan tujuan panelitian yang penulis lakukan adalah sebagai berikut :

Tujuan Penelitian :

a. Menerapkan sistem komputerisasi sebagai alat bantu atau aplikasi dalam mempermudah pengolahan data.

b. Untuk menerapkan penggunaan teknologi informatika.

Manfaat Penelitian :

Disini penulis mendapat banyak manfaat dari penelitian ini diantaranya adalah untuk mengetahui sejauh mana program visual basic 6.0 digunakan.

2. Manfaat Akademik

a. Menambah pembendaharaan dan memperkaya pengetahuan khususnya yang berkaitan dengan kualitas ilmu pengetahuan dan hubungannya dengan pemograman visual basic 6.0 di lingkungan kerja. 
b. Sebagai panduan bagi pihak-pihak yang membutuhkan infomasi .

3. Manfaat Bagi Instansi

Dari hasil penelitian ini diharapakan dapat memberi sumbangan pikiran dan sebagai bahan pertimbangan dalam pengambilan keputusan bagi Kantor Kepala Desa Tanjung Pauh Mudik.

\section{Metode Penelitian}

Dalam penyusunan skripsi ini penulis memerlukan pengumpulan data dan infomasi untuk menyelesaikan tugas skripsi.

\section{Sistematika Penulisan}

Agar tugas skripsi ini terarah, maka penulis akan menjabarkan sistematika penulisan mulai dari bab pendahuluan sampai dengan bab kesimpulan dan saran. Diharapkan pembaca dapat mengetahui secara garis besar isi dari skripsi ini.

\section{METODE PENELITIAN}

Dalam penyusunan skripsi ini penulis memerlukan pengumpulan data dan infomasi untuk menyelesaikan tugas skripsi ini dengan cara sebagai berikut:

a. Metode Penelitian Lapangan (field Research)

Metode ini dilakukan untuk mengumpul data-data yang lengkap dan akurat maka penulis langsung mengadakan penelitian di Kantor Kepala Desa Tanjung Pauh Mudik dengan melakukan pengamatan, pendekatan dan mewawancarai langsung kepada pegawai yang bersangkutan, selain itu juga penulis memperoleh dari sumber-sumber yang dapat dipercaya.

b. Metode Penelitian Kepustakaan (Library Research)

Penelitian ini penulis lakukan dengan mencari, membaca, mempelajari serta memahami yang berhubungan dengan penelitian yang penulis lakukan pada Kantor Kepala Desa Tanjung Pauh Mudik.

c. Metode Penelitian Laboratorium (Laboratotory Research)

Yaitu melakukan pengolahan data terhadap data-data yang telah dikumpulkan melalui penelitian, pengolahan tersebut dengan menggunakan komputer :

1. Hardware

a. Processor Intel(R) Core (TM)2 Duo $\mathrm{CPU}=2,00 \mathrm{~GB}$.

b. Monitor VGA.

c. Keyboar.

d. Mouse.

e. Printer HP deskjet F2410.

2. Software

a. Windows-7.

b. Office 2003

c. Program Visual Basic Versi 6.0.

\section{ANALISA DAN HASIL}

\section{Aliran Sistem Informasi Lama}

Untuk lebih jelasnya dalam menganalisa maka diperlu digambarkan permasalahan dari sistem yang sedang berjalan saat ini, dengan memperhatikan aliran sistem informasi sistem pengolahan data produksi padi sawah melalui kelompok tani pada kantor kepala desa Tanjung Pauh Mudik pada saat ini. Berikut bagan aliran sistem yang sedang berjalan.

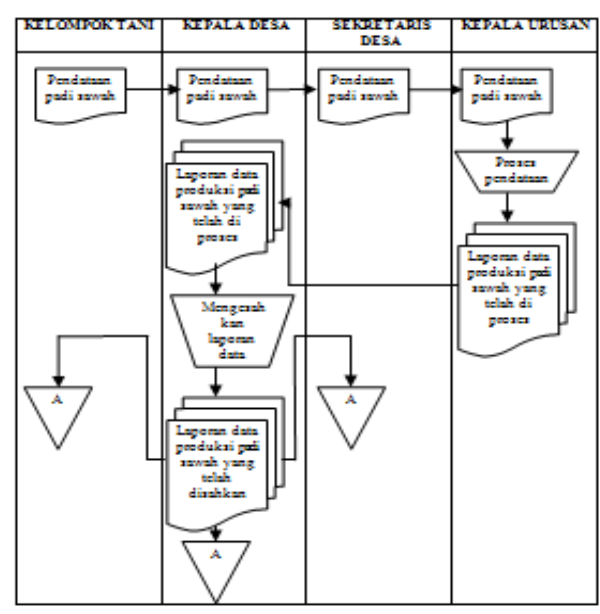

https://ejournal.giciku.ac.id/ STMIK GICl 


\section{Kelemahan Sistem yang Sedang Berjalan}

Adapun kelemahan dalam pembuatan laporan dan pengolahan data produksi padi sawah melalui kelompok tani pada kantor kepala desa Tanjung Pauh Mudik adalah sebagai berikut:

1. Data yang dihasilkan sering terjadi redukasi data yang mengakibatkan terjadinya perbaikan-perbaikan karena tidak menggunakan aplikasi bahasa pemrograman yang berbasis komputer.

2. Waktu yang dibutuhkan dalam proses pembuatan laporan pengolahan data produksi padi sawah melalui kelompok tani pada kantor kepala desa tanjung pauh mudik dalam waktu yang singkat tidak dapat terpenuhi.

\section{Analisa Sistem yang di Usulkan}

Berdasarkan analisa terhadap sistem yang sedang berjalan, maka dilakukan perancangan sistem yang akan diusulkan dengan menggunakan peralatan komputer dengan bahasa pemrograman Visual Basic Versi 6.0 untuk proses pengolahan data pemberian informasi dan pegawai pada kantor kepala desa Tanjung Pauh Mudik. Dengan digunakannya komputer beserta program ini diharapkan dapat memperlancar aktivitas sehari-hari, karena hal tersebut dapat memberikan keuntungan seperti dapat memberikan informasi tentang data padi sawah dengan cepat dan akurat, dapat meningkatkan aktivitas kerja, menghasilkan informasi dengan tingkat ketelitian yang tinggi, dapat mempercepat pengolahan data pegawai.

Adapun sistem informasi yang diusulkan adalah sebagai berikut:

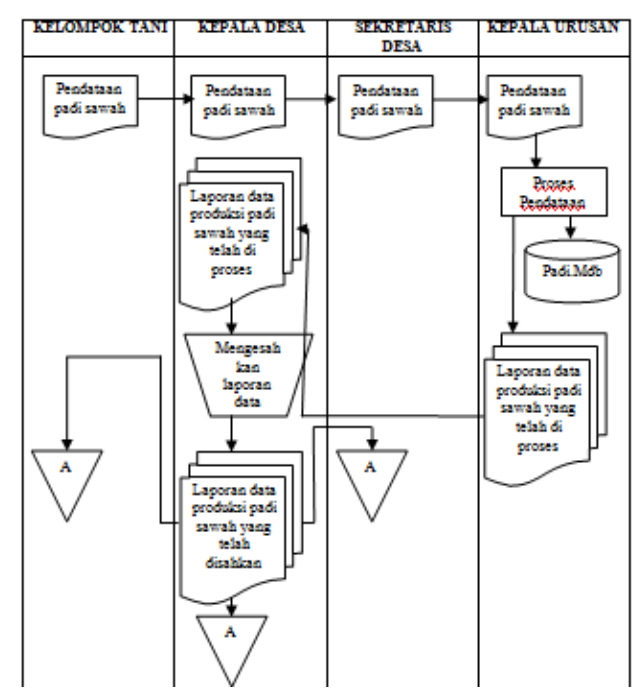

\section{Struktur Global}

Adapun struktur program yang dirancang dalam pengolahan data produksi padi sawah melalui kelompok tani pada kantor kepala desa Tanjung Pauh Mudik adalah sebagai berikut:

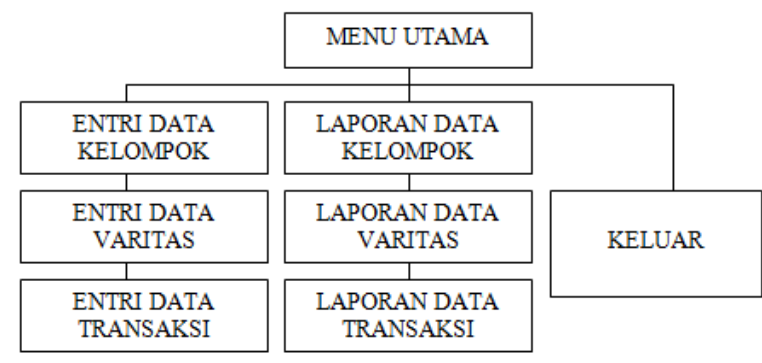

Desain file

File adalah kumpula dari record yang tersusun secara logis dimana record-record tersebut tersimpan pada mediapenyimpanan yaitu harddisk, yang digunakan oleh programer untuk keperluan program. Adapu rancangan file yang penulis gunakan dalam perancangan sistem pengolahan data padi sawah melalui kelompok tani adalah File Entry Data Kelompok, File Entry Data Varitas, File Entry Data Transaksi. 
Volume 5 No. 1

Mei 2017

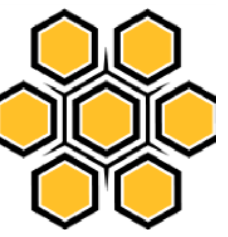

1. Desain File Entry Data Kelompok

1. Desain Input Entry Data Kelompok

Tabel 4.1. Desain File Entry Data Kelompok

ENTRY DATAKELOMPOK
PENGOLAHANDATAPRODUKSI PADI SAWAH MELALU KELOMPOK T ANIDIDESA TANJUNG PAUH MUDIK

Nama Database $\quad$ :Padi.Mdb

Nama Tabel : : Kelompok

Primary Key : :Kd_Kelompok

\begin{tabular}{|c|c|c|c|c|}
\hline No & Field Name & Type & Width & Description \\
\hline 1 & Kd_Kelompok & Text & 4 & Kode Kelompok \\
\hline 2 & Nm_Kelompok & Text & 15 & Nama Kelompok \\
\hline 3 & Jlh_Anggota & Text & 3 & Jumlah Anggota \\
\hline 4 & Kelas_Kelompok & Text & 10 & Kelas Kelompok \\
\hline
\end{tabular}

\begin{tabular}{|c|c|}
\hline KODE KELOMPOK & $\mathrm{X}(4)$ \\
\hline NAMA KELOMPOK & $\mathrm{X}(15)$ \\
\hline JUMLAH ANGGOTA & $\mathrm{X}(3)$ \\
\hline KELAS KELOMPOK & $\mathrm{X}(10)$ \\
\hline
\end{tabular}

\begin{tabular}{|c|c|c|}
\hline KOREKSI & SIMPAN & HAPUS \\
\hline BATAL & SEGAR & KELUAR \\
\hline
\end{tabular}

2. Desain File Entry Data Varitas

Tabel 4.2. Desain File Entry Data Varitas

$\begin{array}{ll}\text { Nama Database } & : \text { Padi.Mdb } \\ \text { Nama Tabel } & : \text { Varitas } \\ \text { Primary Key } & : \text { Kd_Varitas }\end{array}$

\begin{tabular}{|c|c|c|c|c|}
\hline No & Field Name & Type & Width & Description \\
\hline 1 & Kd_Varitas & Text & 4 & Kode Varitas \\
\hline 2 & Nm_Varitas & Text & 15 & Nama Varitas \\
\hline
\end{tabular}

2. Desain input Entry Data Varitas

\begin{tabular}{|c|c|c|}
\hline \multicolumn{3}{|c|}{$\begin{array}{l}\text { ENTRY DATA VARITAS } \\
\text { PENGOLAHANDATAPRODUKSI PADI SAWAHMELALUI } \\
\text { KELOMPOK TANIDIDESATANJUNG PAUHMUDIK }\end{array}$} \\
\hline \multicolumn{2}{|c|}{ KODE VARITAS } & $\mathrm{X}(4)$ \\
\hline \multicolumn{2}{|c|}{ NAMA VARITAS } & $\mathrm{X}(15)$ \\
\hline KOREKSI & SIMPAN & HAPUS \\
\hline BATAL & SEGAR & KELUAR \\
\hline
\end{tabular}

Tabel 4.3. Desain File Entry Data Transaksi

$\begin{array}{ll}\text { Nama Database } & \text { : Padi.Mdb } \\ \text { Nama Tabel } & \text { :Transaksi } \\ \text { Primary Key } & \text { :Kd_Transaksi }\end{array}$

\begin{tabular}{|c|c|c|c|c|}
\hline No & Field Name & Type & Width & Description \\
\hline 1 & Kd_Transaksi & Text & 4 & Kode Transaksi \\
\hline 2 & Kd_Kelompok & Text & 4 & Kode Kelompok \\
\hline 3 & Kd_Varitas & Text & 4 & Kode Varitas \\
\hline 4 & Luas_Sawah & Text & 10 & Luas Sawah \\
\hline 5 & Total_Produksi & Text & 10 & Total Produksi \\
\hline 6 & Bulan & Text & 7 & Bulan
\end{tabular}

\section{Desain Input}

Desain Input adalah rancangan dari input data yang akan diproses. Dalam rancangan ini, juga menampilkan tombol proses.

3. Desain Dyput Entry Data Tranaaksi

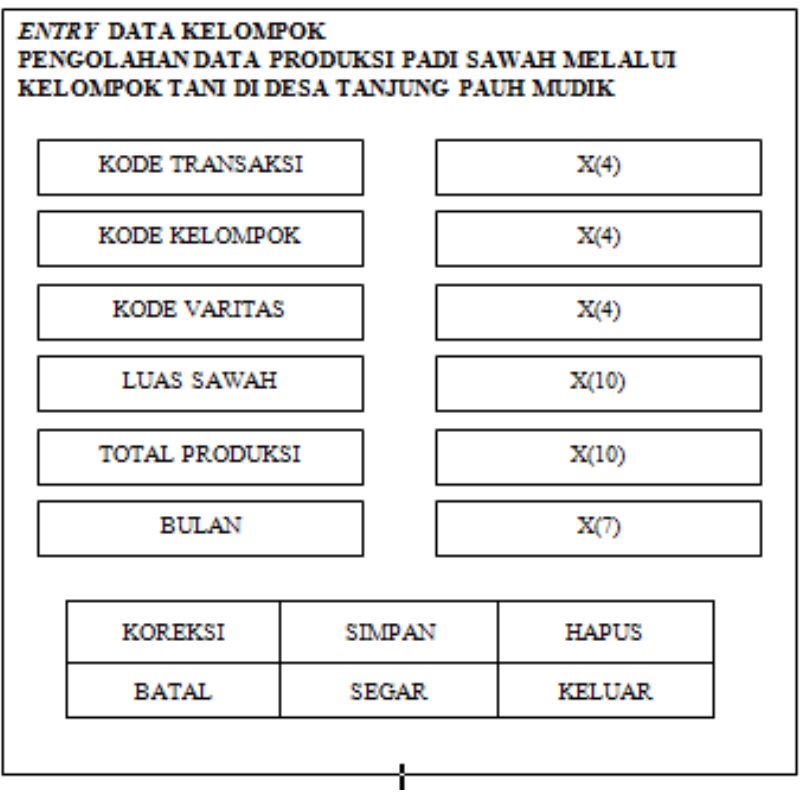




\section{Desain Output}

Desain output merupakan rancangan informasi yang dihasilkan dari suatu sistem atau proses atau program. Berdasarkan analisa laporan-laporan yang ada, penulis mencoba merancang laporan-laporan yang dibutuhkan sistem tersebut.

1. Desain Output Entry Data Kelompok

Tabel 4.4 Desain Output Entry Data Kelompok ENTRY DATA KELOMPOK

PENGOLAHAN DATA PRODUKSI PADI SAIVAH MIFI ALUI KELOMPOK TANI DI DESA TANJUNG PAUH MUDIK

\begin{tabular}{|c|c|c|c|}
\hline Kode Kelompok & Nama Kelompok & Jumlah Anggota & Kelas Kelompok \\
\hline $\mathrm{X}(4)$ & $\mathrm{X}(15)$ & $\mathrm{X}(3)$ & $\mathrm{X}(10)$ \\
\hline & & & \\
\hline
\end{tabular}

2. Desain Output Entry Data Varitas

Tabel 4.5 Desain Output Entry Data Varitas

ENTRY DATA VARITAS

PENGOLAHAN DATA PRODUKSI PADI SAWAH MELALUI KELOMPOK TANI DI DESA TANJUNG PAUH MUDIK

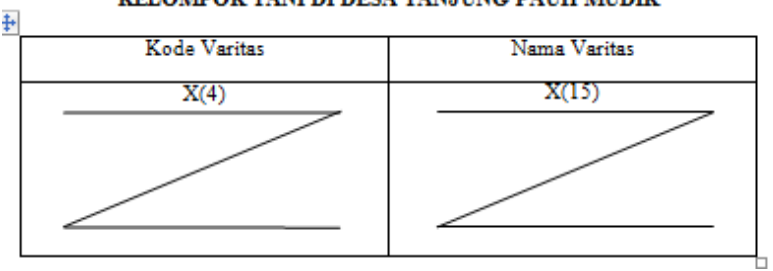

3. Desain Output Entry Data Transaksi

Tabel 4.6 Desain Output Entry DataTransaksi

ENTRY DATA TRANSAKSI

PENGOLAHAN DATA PRODUKSI PADI SAIVAH MELALUI

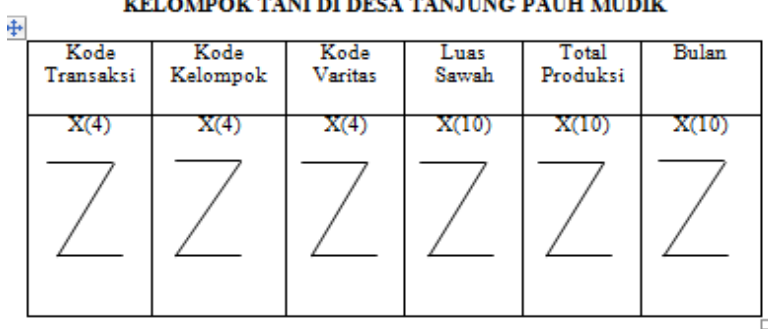

Tanjung Pauh Mudik, 99/99/9999 Kepala Desa Tanjung Pauh Mudik

\section{Aliran Program (Flowchart)}

Flowchart merupakan bagan untuk gambaran yang menjelaskan aliran atau langkah yang ditempuh dari program yang digunakan dari awal sampai akhir secara terperinci. Flowchart penting untuk membantu memeriksa program yang telah selesai dan dapat membantu orang lain memahami program yang dibuat oleh seorang programer yang ditunjukkan dengan simbol anak panah.
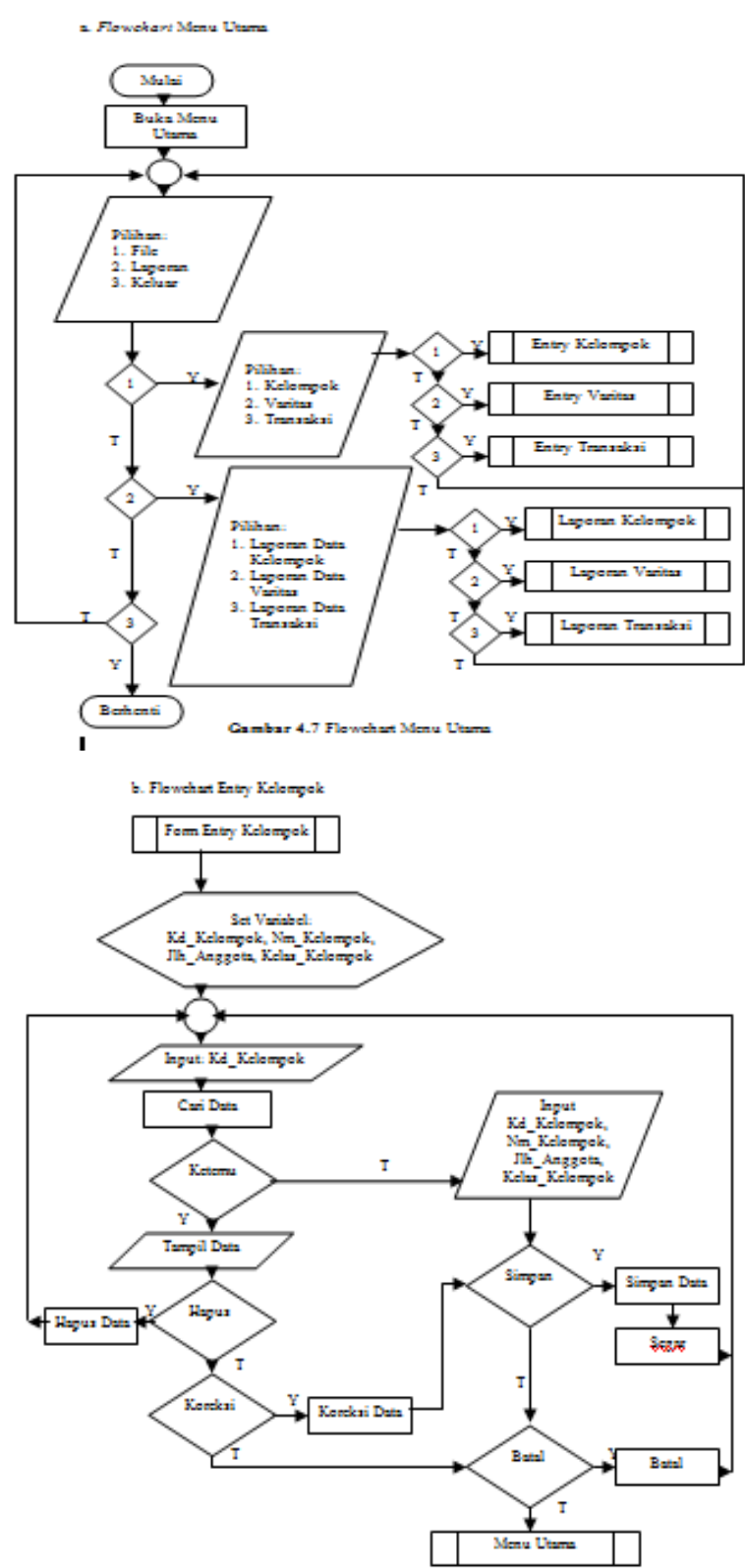

JURSIMA

Jurnal Sistem Informasi dan Manajemen https://ejournal.giciku.ac.id/ STMIK GICl 

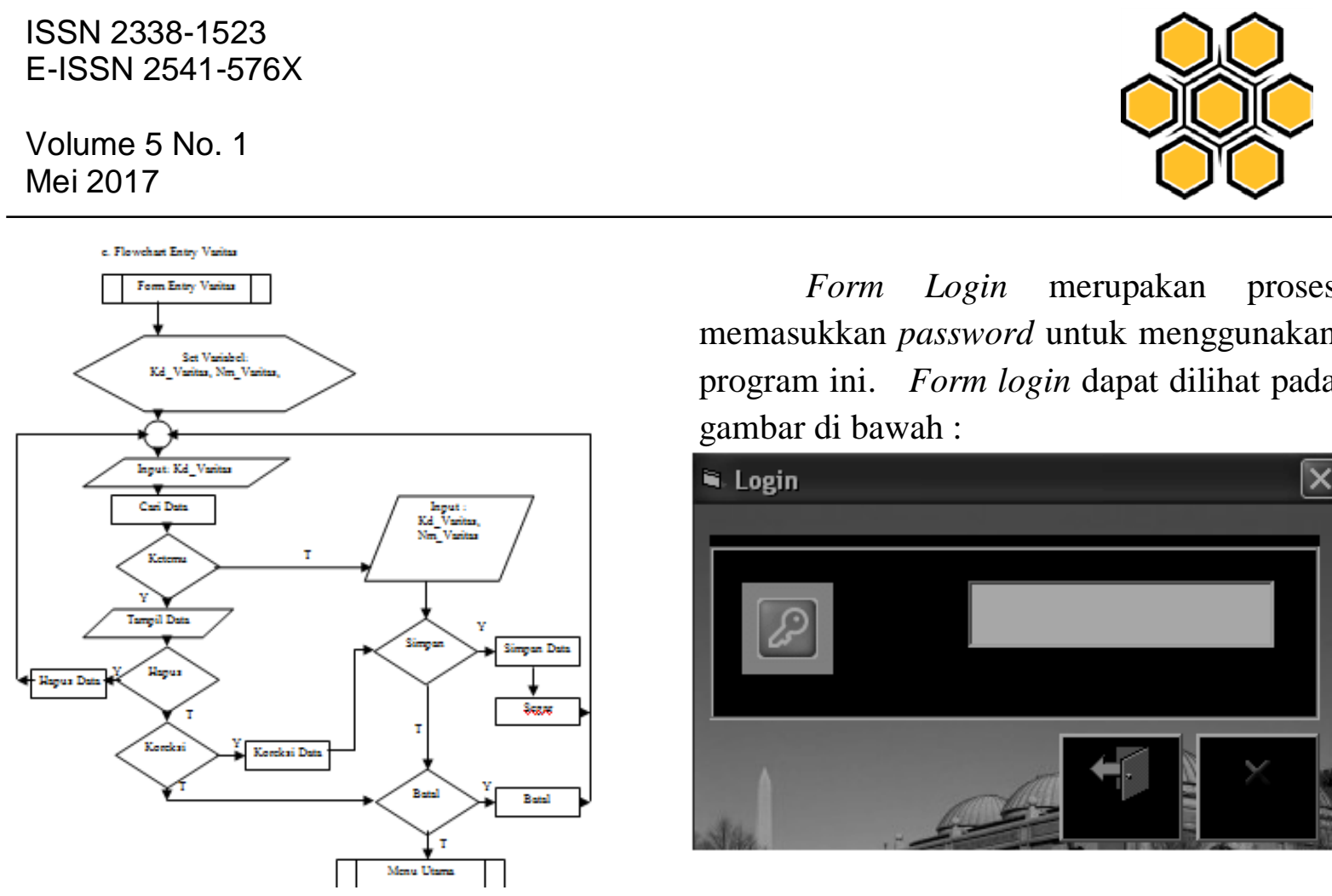

Form Login merupakan proses memasukkan password untuk menggunakan program ini. Form login dapat dilihat pada gambar di bawah :

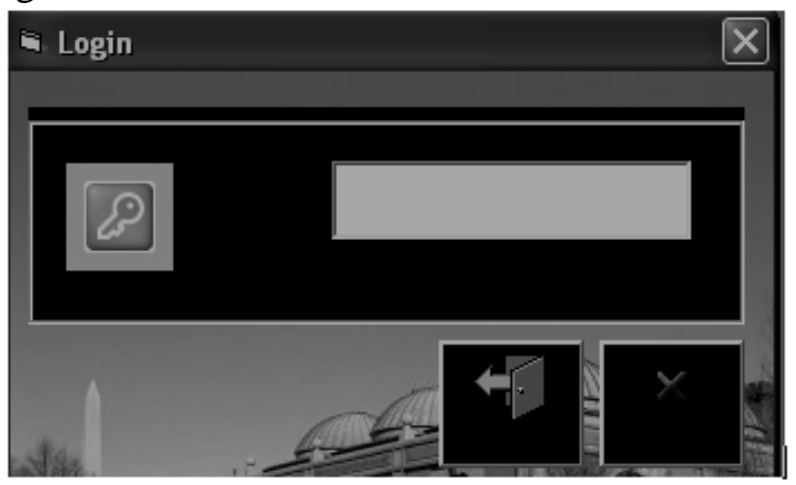

\section{Menu Utama}

Menu Utama merupakan tampilan

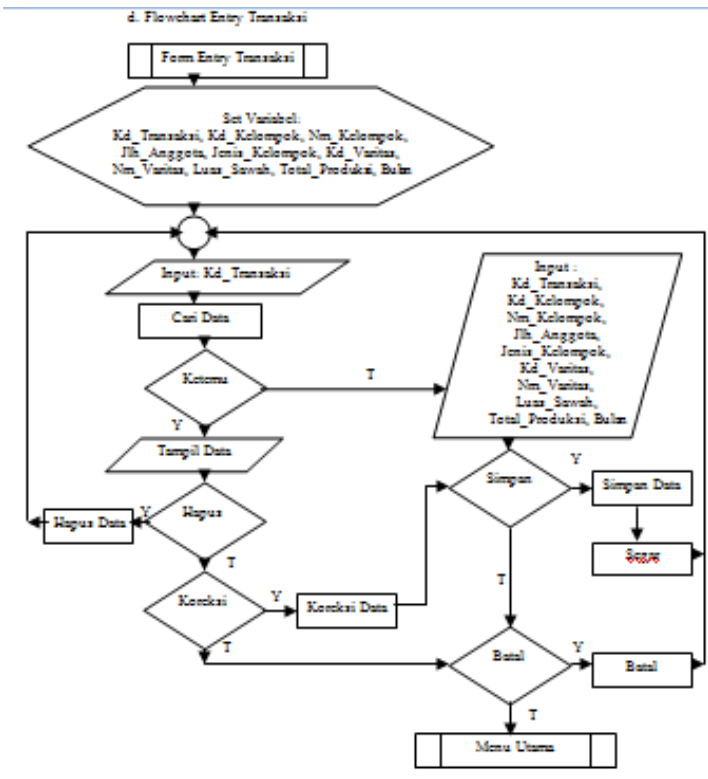

\section{Hasil Implementasi Sistem}

\section{Form Login}

Form login merupakan tampilan pertama dari Sistem Informasi Produksi Padi Sawah Melalui Kelompok Tani Pada Kantor Kepala Desa Tanjung Pauh Mudik. Menu Utama terdiri dari sub-sub menu yaitu: Sub menu Entri, Sub menu Laporan dan Terakhir Sub menu Keluar. Sub menu ini disusun sesuai dengan urutan kerja yang harus dijalankan dalam implementasi sistem. Form Menu Utama dapat dilihat pada gambar di bawah :

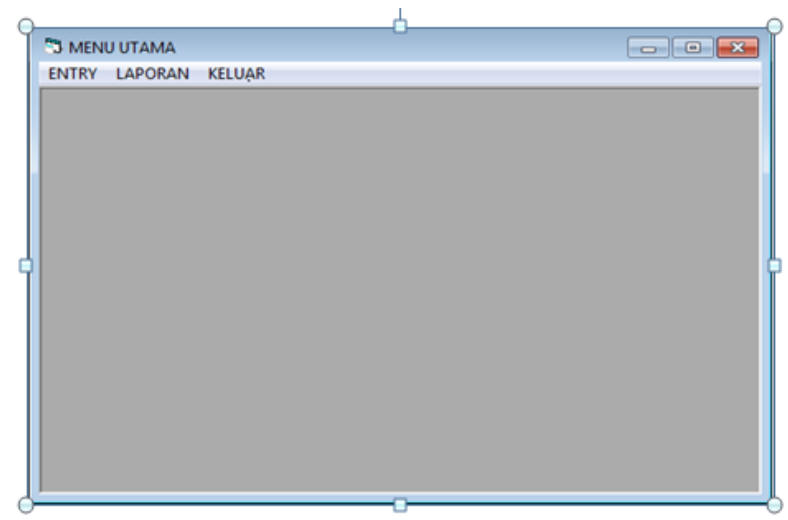
pertama dari Sistem Informasi Produksi Padi Sawah Melalui Kelompok Tani Pada Kantor Kepala Desa Tanjung Pauh Mudik. 


\section{Entri Kelompok}

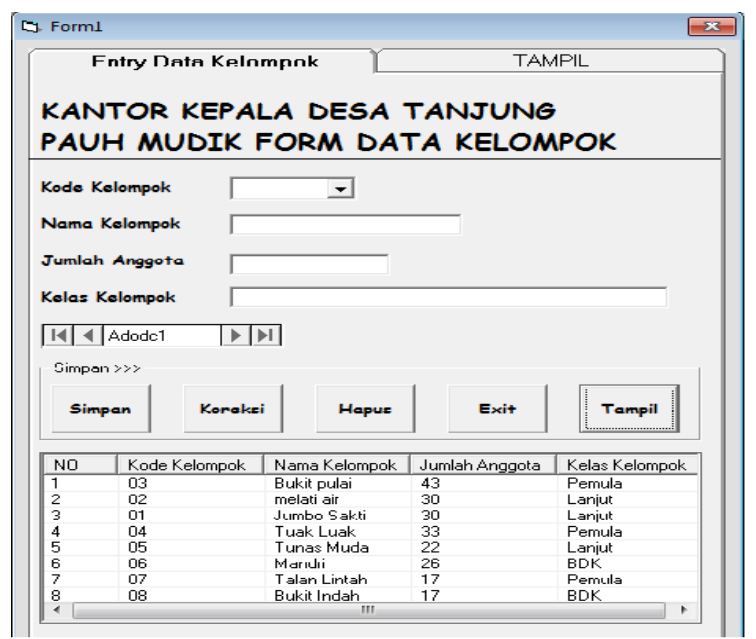

Pada Form Input data kelompok yang dientrikan adalah kode kelompok, nama kelompok, jumlah anggota dan kelas kelompok. Data ini akan disimpan pada tabel kelompok. Pada Form ini disediakan lima tombol yaitu Simpan, Koreksi, Hapus, Tampil dan Keluar. Tombol simpan berfungsi untuk menyimpan data kelompok yang di Inputkan. Tombol Koreksi berfungsi untuk memperbaiki atau mengkoreksi data-data kelompok yang sudah dientrikan. Tombol Hapus berfungsi untuk menghapus data kelompok yang salah. Tombol Tampil berfungsi untuk menampilkan data kelompok di list view, Tombol keluar berfungsi sebagai perintah keluar dari Form.

\section{Entri Varitas}

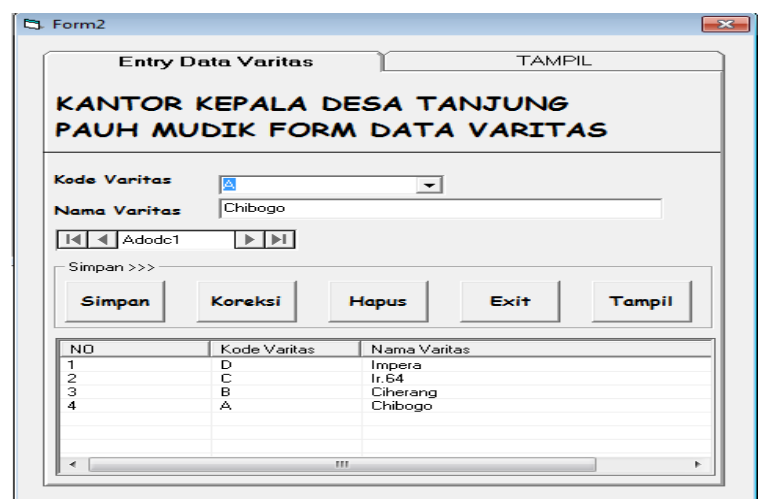

Pada Form Input data varitas yang dientrikan adalah kode varitas dan nama varitas. Data ini akan disimpan pada tabel varitas. Pada Form ini disediakan lima tombol yaitu Simpan, Koreksi, Hapus, Tampil dan Keluar. Tombol simpan berfungsi untuk menyimpan data varitas yang di Inputkan. Tombol Koreksi berfungsi untuk memperbaiki atau mengkoreksi data-data varitas yang sudah dientrikan. Tombol Hapus berfungsi untuk menghapus data varitas yang salah. Tombol Tampil berfungsi untuk menampilkan data varitas di list view, Tombol keluar berfungsi sebagai perintah keluar dari Form.

\section{Entry Transaksi}

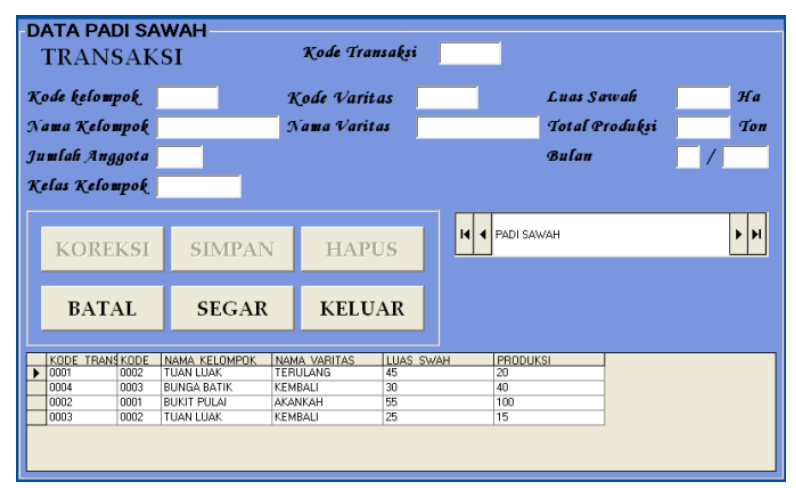

Pada Form Input Data Transaksi yang di inputkan adalah : kode kelompok kemudian melalui "searching" pada tabel entri kelompok menemukan kode kelompok. Dan secara otomatis akan muncul nama kelompok, jumlah anggota dan kelas kelompok. Input kode varitas kemudian melalui "searching" pada tabel entri varitas menemukan kode varitas dan secara otomatis akan muncul nama varitas. Input id petugas kemudian melalui "searching", Data lain yang dientri adalah bulan, luas sawah dan total produksi. Pada Form ini disediakan lima tombol yaitu Simpan, Koreksi, Hapus, Tampil dan Keluar. Tombol simpan berfungsi untuk menyimpan data produksi padi sawah yang di Inputkan.
JURSIMA

Jurnal Sistem Informasi dan Manajemen https://ejournal.giciku.ac.id/ STMIK GICl 
Tombol Koreksi berfungsi untuk memperbaiki atau mengkoreksi data-data produksi padi sawah yang sudah dientrikan. Tombol Hapus berfungsi untuk menghapus data produksi padi sawah yang salah. Tombol Tampil berfungsi untuk menampilkan data produksi padi sawah di list view, Tombol keluar berfungsi sebagai perintah keluar dari Form.

\section{Sub Menu Laporan}

Sub menu laporan adalah sub menu yang disediakan untuk seluruh laporan data produksi padi sawah. Pada sub menu laporan terdiri dari 3 Form laporan yaitu Form laporan data kelompok, Form laporan data varitas dan Form laporan produksi padi sawah.

Adapun bentuk laporan yang dihasilkan adalah sebagai berikut:

\section{Laporan Data Kelompok}

KANT OR KEPALA DESA T ANJUNG PAUH MUDIK LAPORAN DATAKELOMPOK

\begin{tabular}{|c|c|c|c|}
\hline Kd kelompok & Nm kelompok & Jlh Anggota & Kelas Kelompok \\
\hline 03 & Bukit pulai & 43 & Pemula \\
\hline 02 & melati air & 30 & L anjut \\
\hline 01 & Jumbo Sakti & 30 & Lanjut \\
\hline 04 & Tuak Luak & 33 & Pemula \\
\hline 05 & Tunas Muda & 22 & Lanjut \\
\hline 06 & Mandri & 26 & BDK \\
\hline 07 & Talan Lintah & 17 & Pemula \\
\hline 08 & Bukit Indah & 17 & $\mathrm{BDK}$ \\
\hline
\end{tabular}

\section{Laporan Data Varitas}

KANT OR KEPALA DESA TANJUNG PAUH MUDIK LAPORAN DATA VARIT AS

\begin{tabular}{|l|l|}
\hline 10/16/2012 \\
\hline Kd Varitas & Nm Varitas \\
\hline D & Impera \\
\hline C & Ir.64 \\
\hline B & Ciherang \\
\hline A & Chibogo \\
\hline
\end{tabular}

\section{Form Laporan Transaksi}

Laporan data produksi padi sawaTransaksi perbulan dihasilkan dari tabel kelompok, tabel varitas, tabel petugas dan tabel produksi. Tampilan laporan data produksi padi sawah perbulan dapat dilihat pada gambar 5.15:

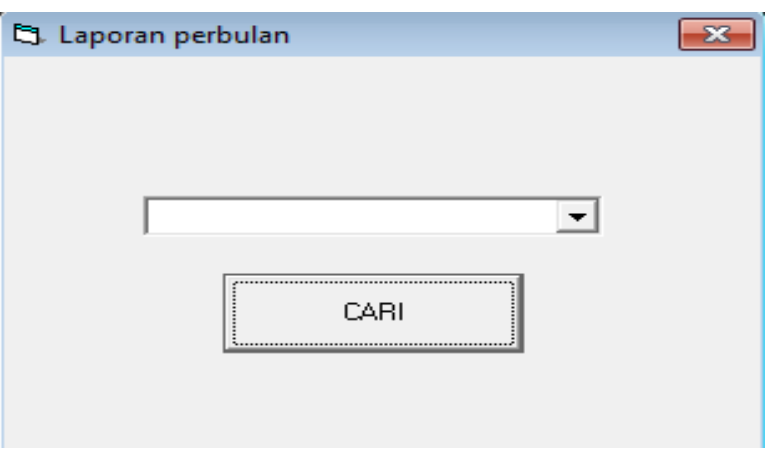

Setelah data di entrikan dan memilih Bulan dan di klik cari maka akan muncul laporan seperti pada gambar di bawah ini :

\begin{tabular}{|c|c|c|c|c|c|c|c|}
\hline \multicolumn{8}{|l|}{ 1019201 } \\
\hline $\begin{array}{c}\text { Nama } \\
\text { Kelompok }\end{array}$ & $\begin{array}{c}\text { Jlh } \\
\text { Anggota }\end{array}$ & $\begin{array}{c}\text { Kelas } \\
\text { Kelompok }\end{array}$ & $\begin{array}{l}\text { Nama } \\
\text { Varitas }\end{array}$ & $\begin{array}{c}\mathrm{Nm} \\
\text { Petugas }\end{array}$ & Jabatan & $\begin{array}{l}\text { Luas } \\
\text { Sawah }\end{array}$ & $\begin{array}{c}\text { Total } \\
\text { Prod uksi }\end{array}$ \\
\hline melati air & 30 & Lanjut & Ir.64 & Nasrul Hadi & KADES & $7,5 \mathrm{Ha}$ & 40 Ton \\
\hline Jumbo Sakti & 30 & Lanjut & Chibogo & SUHARTO & PPL & $10 \mathrm{Ha}$ & 56 Ton \\
\hline Bukit pulai & 43 & Pemula & Impera & Irahmat & SEKDES & $10 \mathrm{Ha}$ & 55 Ton \\
\hline Tuak Luak & 33 & Pemula & Ciherang & Nassrul Hadi & KADES & $10 \mathrm{Ha}$ & 60 Ton \\
\hline JUMLAH & 136.00 & & & & & & \\
\hline TOTAL & & & & & & $7,5 \mathrm{Ha}$ & 60 Ton \\
\hline
\end{tabular}

\section{PENUTUP}

\section{Kesimpulan}

Dari hasil analisa dan pembahasan yang telah dilakukan pada bab-bab terdahulu penulis dapat menarik kesimpulan sehubungan dengan perancangan Sistem Pengolahan Data Padi Sawah Melalui Kelompok Tani pada Kantor Kepala Desa Tanjung Pauh Mudik sebagai berikut :

a. Sistem Pengolahan Data Produksi Padi Sawah Melalui Kelompok Tani pada Kantor Kepala Desa Tanjung Pauh Mudik masih dilakukan secara manual. Semua
JURSIMA

Jurnal Sistem Informasi dan Manajemen https://ejournal.giciku.ac.id/ STMIK GICI 
penyimpanan data pada media penyimpanan yang telah ada kurang terjamin.

c. Sistem Pengolahan Data Produksi Padi Sawah Melalui Kelompok Tani pada Kantor Kepala Desa Tanjung Pauh Mudik yang telah dirancang akan lebih dirasakan manfaatnya yaitu memberi informasi yang tepat dan akurat. Dengan demikin penyimpangan-penyimpangan atau kelemahan-kelemahan yang selama ini terjadi dapat diatasi.

\section{Saran}

Dari hasil penelitian sejak dari awal sampai akhir, penting bagi penulis memberikan saran sebagai berikut:

a. Diharapkan Kepada Kantor Kepala Desa Tanjung Pauh Mudik dapat memaksimalkan penggunaan program yang telah dibuat untuk pengolahan data produksi padi sawah melalui kelompok tani sebagai alat bantu untuk mempercepat pengolahan data agar tercipta hasil kerja yang efesien.

b. Melakukan pelatihan untuk tenaga kerja agar pada saat implementasinya tidak akan terjadi kesalahan, misalnya pada pemasukan data, pengaksesan data serta pembuatan laporan yang dibutuhkan.

c. Pada penerapan sistem baru ini perlu adanya tenaga profesional dalam pengoperasian komputer.

d. Pada sistem informasi pengolahan data produksi padi sawah ini tentu saja masih ada kekurangan-kekurangan, untuk disarankan bagi penelitian selanjutnya untuk melanjutkan penelitian ini agar dapat menambah laporan dan informasi lainnya, sehingga lebih mendukung pengolahan data padi sawah pada masa yang akan datang. e. laporan-laporan yang akan dibuat untuk waktu untuk selanjutnya, dapat dilihat perbandingannya untuk laporan-laporan sebelumnya untuk membantu pengambilan keputusan.

\section{DAFTAR PUSTAKA}

Abdul Kadir. Pengenalan Sistem Informasi, Andi Yogyakarta, 2002.

Arief Ramadhan "Visual Basic 6.0". Elex Media Kumputindo 2004.

Budi Sutedjo Dharma Oetomo, S.Kom.,MM."Perancangan dan pembangunan sistem informasi”, Andi Yogyakarta 2002.

Jogianto Hartono, MBA, h.D. "Pengenalan Komputer”, Andi, Yogyakarta, 1999.

Kusrini, M.Kom., dkk "Tuntunan Praktis Membangun Sistem informasi Akuntansi dengan visual basic dan Microsoft SQL Server", Andi Yogyakarta 2007.

Madcoms "Pemrograman Tingkat Lanjut dengan Visual Basic 6.0 dan Crystal Report" Andy Yogyakarta 2005.

"Aplikasi Database dan Crystal Report pada Visual Basic 6.0” Andy Yogyakarta 2005

Tata Sutabri, S.Kom., MM. Sistem Informasi Manajemen, Andi, Jakarta, 2005.

Anton Athoillah,M.M,Dr,H,M, Dasar-dasar Manajemen, CV Pustaka Setia, Bandung,2010.

Subari \& Yuswanto. Pemrograman Visual Basic 6.0, CERDAS PUSTAKA PUBLISHER, Jakarta, 2008.

Abdul Razak, Visual Basic 6.0, INDAH, Surabaya,2004.
JURSIMA

Jurnal Sistem Informasi dan Manajemen https://ejournal.giciku.ac.id/ STMIK GICI 